\title{
Energy Generation from Osmotic Pressure Difference Between the Low and High Salinity Water by Pressure Retarded Osmosis
}

\author{
Xu Wang ${ }^{a,{ }^{*}}$, Zhongmai Huang ${ }^{a}$, Lei Li ${ }^{b}$, Shusheng Huang ${ }^{c}$, Eileen Hao Yu ${ }^{d}$ and Keith Scott ${ }^{d}$ \\ ${ }^{a}$ School of Resource and Environmental Science, Wuhan University, Wuhan 430072, China \\ ${ }^{b}$ School of Chemistry and Chemical Engineering, Jiao Tong University, Shanghai 200240, China \\ ${ }^{c}$ EnvWater Co. Ltd, Wuhan 430072, China \\ ${ }^{d}$ School of Chemical Engineering and Advanced Materials, Merz Court, Newcastle University, Newcastle \\ upon Tyne, NE1 7RU, UK
}

\begin{abstract}
Osmosis is a natural phenomenon and exists widely from the salinity gradient between sea water and fresh water. This green energy can be captured using pressure retarded osmosis (PRO). A potential energy of 2.5 terawatts is available globally from rivers flowing into the sea. Membrane is the key component and it has been the main limitation for this technique. The most challenging problem is the internal concentration polarization (ICP) which reduces the water flux by up to $80 \%$. This paper reviews most critical and recent publications on membrane fabrication (e.g. composite membrane, hollow fibber membrane). Summary and perspectives will be given in order to prepare high performance membranes.
\end{abstract}

Keywords: Osmosis, pressure retarded osmosis, membrane, concentration polarization.

\section{INTRODUCTION}

With the growing population and life expectation, energy demand is predicted to increase rapidly in the future. Currently, the energy production from fossil fuels is predominant and it raises a lot of severer issues such as global warming and environmental pollutions. Developing sustainable energy techniques is the only solution to maintain the long-term prosperity of our society. In 1954, the concept of harvesting electric power from mixing fresh and salt water was proposed by Pattle for the first time [1]. A maximum energy of 0.8 $\mathrm{kW} \mathrm{m}{ }^{-3}$ can be captured when $1.0 \mathrm{~m}^{3}$ river water is mixed with $1.0 \mathrm{~m}^{3}$ seawater or with a large surplus of seawater and the global reservation of the osmotic energy is around 2.5 terawatts [2, 3]. However, 980 GW of this osmotic energy is accessible using PRO technique [2]. So far, the development of osmotic power is still in infancy. Compared to other renewable energy techniques (e.g. Wind turbine and Solar cell), PRO has several advantages including stable power out-put and low cost (construction and daily operation).

Using PRO technique to capture the salinity gradient energy was proposed by Sidney Loeb in 1975 [4]. After that, the studies of PRO process for power generation has been continuously conducted from the salinity-energy sources such as the Dead Sea and Great Salt Lake by Loeb and co-workers [5-11].

*Address corresponding to this author at the School of Resource and Environmental Science, Wuhan University, Wuhan 430072, China; Tel: (+86) 41268219409; Fax: (+44)1912225292; E-mail: ryanwang316@qq.com

E-ISSN: 1929-6002/12
McGinnis et al. proposed a closed cycle PRO process (i.e. osmotic heat engine) to exploit the osmotic power generated using a concentrated ammonia-carbon dioxide draw solution [12]. In November 2009, the world first PRO power plant was built with a capacity of $4.0 \mathrm{~kW}$ in Tofte, Norway and operated by a leading energy company - Statkraft [13]. They also claimed a full-scale $25 \mathrm{MW}$ osmotic power plant is planned to build by 2015 .

\section{THE PRINCIPLE OF PRO}

PRO relies on the utilization of large osmotic pressure differentials across semi-permeable membranes to generate water flux. In Figure 1a, the water flux is indicated under different operations including forward osmosis, pressure retarded osmosis and reverse osmosis, respectively. For a FO process, $\Delta P$ is zero; for $R O, \Delta P>\Delta \pi$; and for $P R O, \Delta \pi>\Delta P$. Flux directions and driving forces for the three processes were characterized in the early 1980 s by Lee et al. [14]. The FO point, PRO zone, and RO zone, along with the flux reversal point, are illustrated in Figure 1b.

The principle of PRO power plant can be illustrated in Figure 2a. When seawater (or brine from reverse osmosis) and fresh water (such as river water or secondary fresh water-e.g. waste water) are separated by a semi-permeable membrane, water will diffuse from the feed solution side into the draw solution side which is the seawater side that is pressurized. The pressurized and diluted seawater is then split into two 

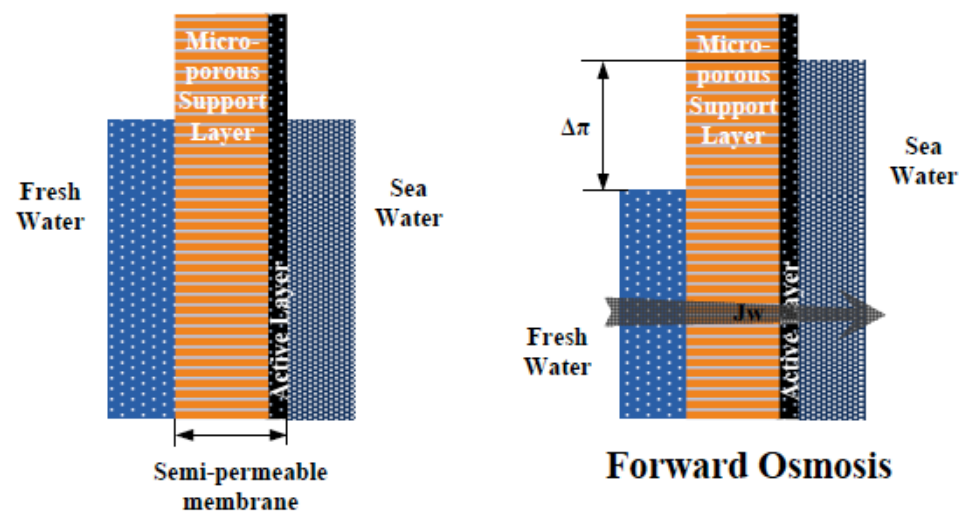

\section{Forward Osmosis}

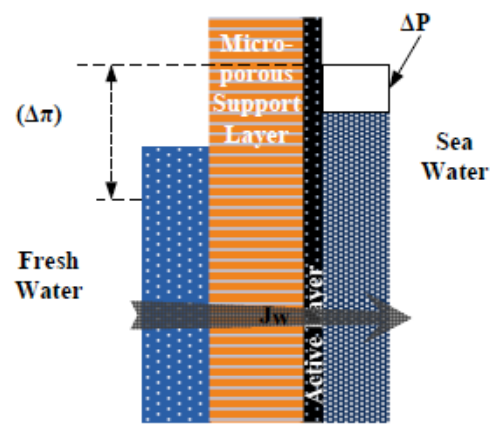

Pressure Retarded

Osmosis

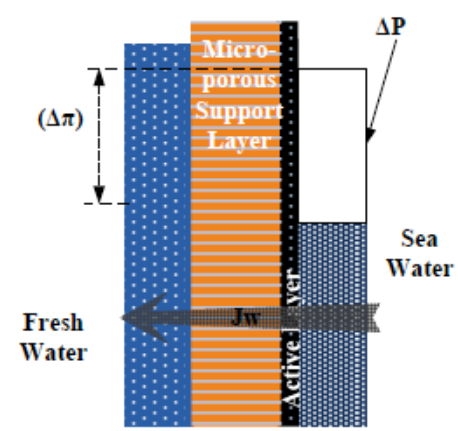

\section{Reverse Osmosis}

(a)

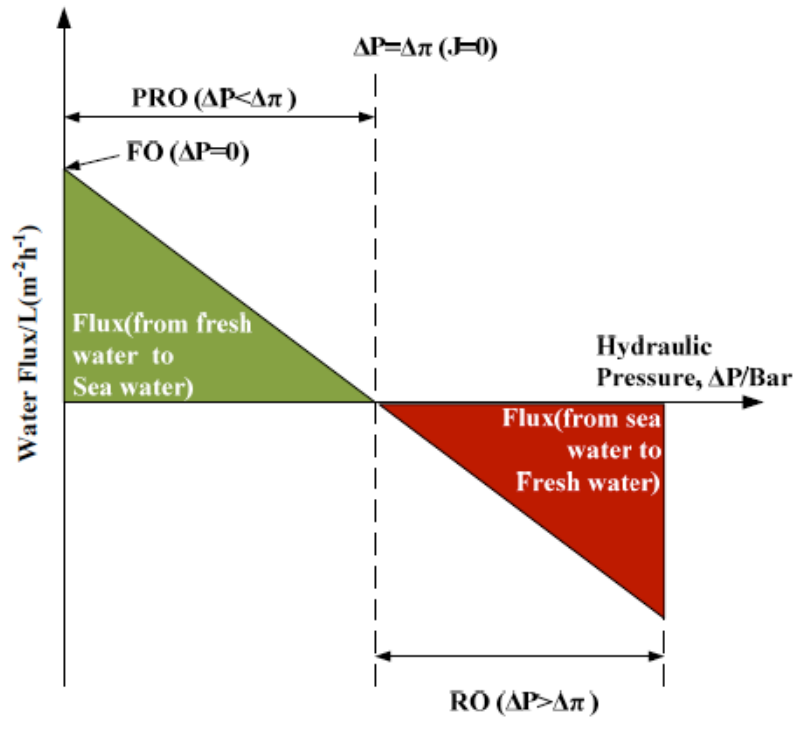

(b)

Figure 1: Schematic diagrams of a) different membrane separation processes, b) plot of water flux with changing pressure across the membrane.

streams: one going through a hydroturbine to generate power by depressurizing the diluted seawater, and the other one passing through a pressure exchanger to assist in pressuring the seawater and thus maintaining the circulation [3]. In a PRO process, power density
$(W)$ is normalized by the membrane area (e.g. $\left.\mathrm{m}^{2}\right)$ and it is commonly used to represent the energy conversion efficiency of the membrane. It can be written as follow:

$$
W=J_{W} \Delta P
$$


where $\Delta P$ is the hydraulic pressure different across the membrane, $J_{w}$ is the water flux and it can be expressed by Eq. (2):

$$
J_{W}=A(\Delta \pi-\Delta P)
$$

where $A$ is the water permeability coefficient of the membrane and $\Delta \pi$ is the solution osmotic pressure differential across the membrane. Combining Eq. (1) and (2),

$W=A(\Delta \pi-\Delta P) \Delta P=-A\left(\Delta P-\frac{\Delta \pi}{2}\right)^{2}+A \frac{\Delta \pi^{2}}{4}$

It can be seen from Figure $\mathbf{2} \mathbf{b}$ that when the hydraulic pressure is equal to the half of the osmotic pressure across the membrane, the power density reaches maximum theoretical value and suggesting the optimal working condition for a PRO power plant. From Eq. (3), the maximum power density value can be obtained as in Eq. (4):

$W_{\max }=A \frac{\Delta \pi^{2}}{4}$

\section{MEMBRANE STRUCTURE AND PARAMETERS}

The PRO system performance mainly relies on the membrane performance which is determined by the membrane structure. For a skin active layer, $A$ in Eq. (2) represents the ability of water diffuse through the active layer and there is another parameter for

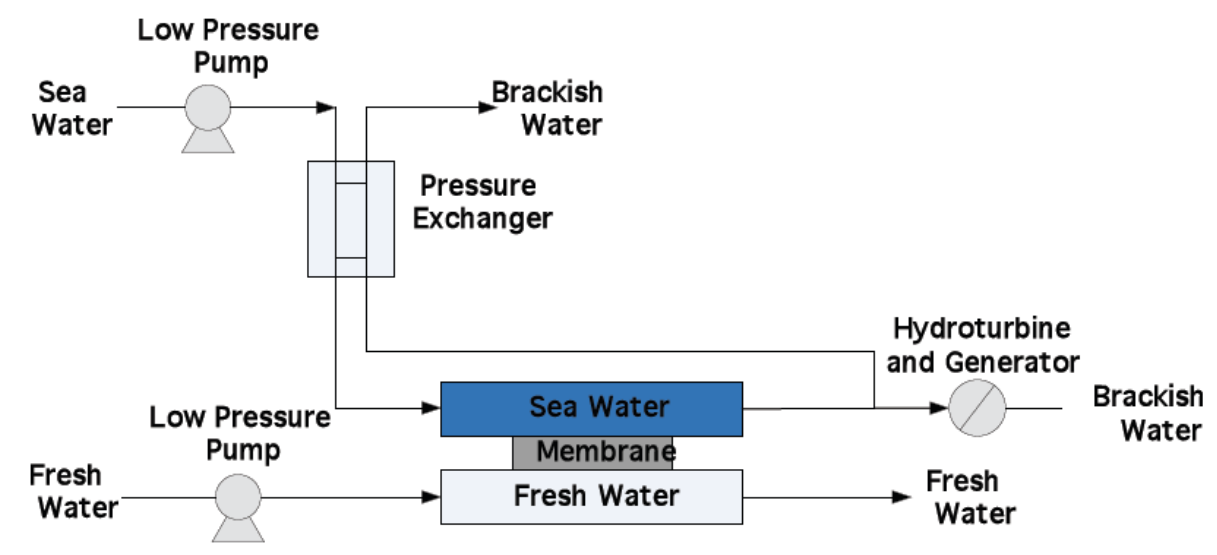

(a)

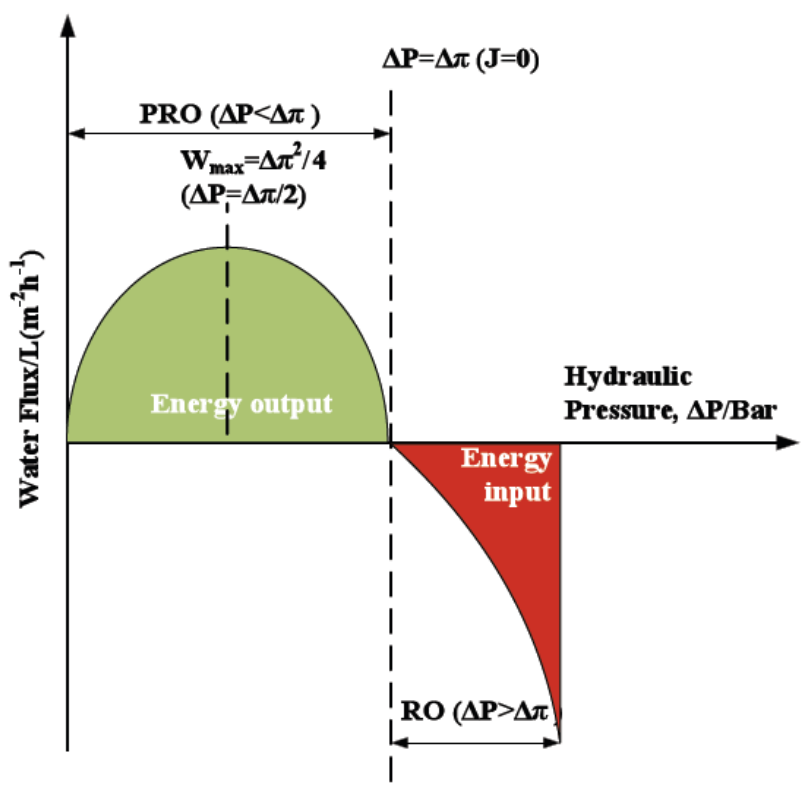

(b)

Figure 2: Schematic diagrams of a) PRO power plant and b) Energy consumption/production in FO, PRO and RO using semipermeable thin film. 
evaluation, which is B-the salt permeability, can be described as follow:

$J_{s}=B \Delta C_{\text {salt }}$

where $\Delta \mathrm{C}_{\text {salt }}$ is the concentration different of salt between feed and draw solution. In theory, the desired skin active layer should possess a high $A$ and low B, namely high water permeability coefficient and low salt permeability. However, there are many studies suggested that there is strong trade-off between two parameters.

In a thin-film composite membrane, the structure of porous support layer can be expressed using Eq. (6):

$S=x \times \tau / \varphi$

where $\mathrm{T}$ is the tortuosity, $\varphi$ is the thickness of porous support layer, $\varphi$ is the porosity. In general, the lower the structure parameter $S$, the better the performance of the membrane under PRO operations is.

\section{CONCENTRATION POLARIZATIONS IN PRO}

In osmotic and pressure-driven processes, concentration polarization is a natural phenomenon and it is inevitable. A typical membrane for PRO (in Figure 3) comprises a layer of rejection active layer which is thin (e.g. $<1 \mu \mathrm{m})$ and dense, and a microporous support layer for providing the adequate mechanical strength. In PRO, the fresh water (feed solution) is directed against the support layer as shown in Figure 3 when osmotic pressure gradients are used to generate electricity [15]. Water transports from the fresh water side to the sea water side. Ideally, the osmotic pressure across the membrane is driven by the concentration difference between the bulk concentration of fresh water $-C_{1}$ and the bulk concentration of sea water $-C_{5}$. However, when the fresh water flows on the active layer of the membrane, solutes build up at the active layer that causing the fresh water concentration at the surface of microporous layer increase from $C_{1}$ to $C_{2}$. This is called concentrative external $\mathrm{CP}$ and is similar to the $\mathrm{CP}$ in pressure-driven membrane processes (e.g. reverse osmosis) [16]. This CP on the feed side of a membrane is a significant problem in pressure-driven membrane desalination processes. This phenomenon inhibits permeate flow due to an increased osmotic pressure at the membrane active layer interface on the feed side of the micro-porous layer. In an osmotic process, this phenomenon occurs on both sides of the membrane with the effect being dilutive on the permeate side, namely dilutive $\mathrm{CP}$ (decrease from $\mathrm{C}_{5}$ to $\mathrm{C}_{4}$ ). Both concentrative and dilutive external $\mathrm{CP}$ can be reduced by deliberately creating turbulence at both sides of the membrane while operating the system unit. It has been suggested that the external CP has a minor effect on the membrane performance [17].

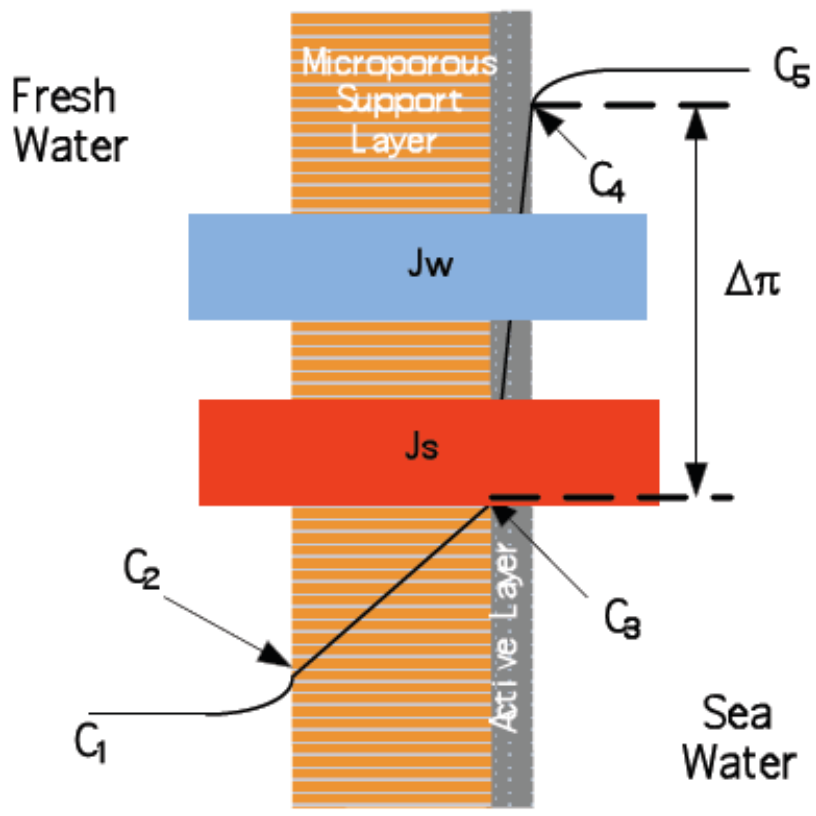

Figure 3: Schematic diagram of the external and internal concentration polarization of the membrane in PRO.

ICP occurs within the micro-porous support layer and leads to the concentration of fresh water at the surface of active layer (feed solution side) increase from $\mathrm{C}_{2}$ to $\mathrm{C}_{3}$. It cannot be mitigated by hydrodynamics such as turbulence and hence drastically reduces the osmotic driving force. So far, it has been established that the water flux decline in $\mathrm{FO}$ is predominantly caused by ICP [15, 18-20]. The earliest FO studies found that ICP could reduce the water flux by more than $80 \%[21,22]$.

The water flux in terms of membrane parameters in PRO processes can be written as following equation $[23,24]$ :

$\operatorname{In}\left[\frac{\left(A \pi_{D}-A \Delta P-J_{V}\right)+B\left(A \Delta P / J_{V}\right)+1}{A \pi_{F}+B\left(\left(A \Delta P / J_{V}\right)+1\right)}\right]=\frac{J_{V}}{K_{m}}$

where $B$ is the solute permeability of the semipermeable active layer; $\pi_{D}$ and $\pi_{F}$ are the osmotic pressures of the draw solution and the feed water, respectively; $\mathrm{Km}$ is the mass transfer coefficient in the membrane substrate, which is the ratio of solute diffusivity in water $(D)$ over the structure parameter $(S)$ of the membrane support layer. The $S$ is defined as the 
product of membrane support layer thickness $(I)$ and tortuosity $(T)$ over its porosity $(\varepsilon)$ :

$$
K_{m}=\frac{D}{S}=\frac{\varepsilon D}{\tau l}
$$

Therefore, the power density $\left(\mathrm{W} \mathrm{m}^{-2}\right)$ can be expressed as:

$$
W=J_{V} \times \Delta P=K_{m} \text { In }\left[\frac{\left(A \pi_{D}-A \Delta P-J_{V}\right)+B\left(\left(A \Delta P / J_{V}\right)+1\right)}{A \pi_{F}+B\left(\left(A \Delta P / J_{V}\right)+1\right)}\right] \times \Delta P
$$

If there is no hydraulic pressure difference across the membrane, i.e., $\Delta P=0$, a simplified Eq. (3) can be used to express water flux in the FO process. The above Eq. (9) indicates that the power output from a PRO power plant is mainly depend on the membrane performance when the feed and draw solutions have relatively constant concentration.

In addition, reverse solute diffusion $\left(\mathrm{J}_{\mathrm{s}}\right)$ (in Figure 3) in osmotically driven membrane processes is also inevitable due to the concentration differences. It has been well established the adverse effects (e.g. membrane fouling) for FO and PRO processes. The details of this phenomenon can be found in previous publications $[3,16,25,26]$.

\section{CELLULOSE ACETATE MEMBRANES}

The membrane in the PRO process is the key component. The requirement for a good PRO membrane is high water flux together with a low salt permeability [27]. To make PRO profitable, the power density of the PRO system was determined to be between 4-6 $\mathrm{W} / \mathrm{m}^{2}$ [27]. However, the development of PRO has been hindered for many years by the lack of high performance membrane particularly with adequate water flux. For example, a power density between 0.11 and $1.22 \mathrm{Wm}^{-2}$ was yielded using existing reverse osmosis membranes in a pressure retarded osmosis application on seawater and fresh water (osmotic pressure difference $\Delta \pi=20-25$ bar) [28]. The thick support layers of those RO membranes contributed to severe ICP which reduce the water flux and power density [28].

Cellulose acetate has many advantageous characteristics such as relatively high hydrophilicity that favors high water flux and low fouling propensity, good mechanical strength, wide availability and good resistance to degradation by chlorine and other oxidants [3, 29, 30]. The history of using CA as material for membrane separation can go back as early as 1950s [31, 32]. The later breakthrough was made by Loeb and Sourirajan, and the asymmetric CA membrane became viable for membrane separation especially for RO process [33]. Hydration Technology Innovations (HTI) is a leading company on forward osmosis technique. Currently, two types of membrane which are cellulose triacetate (CTA) membrane and thin composite membrane are commercially available from this company. There have been extensive investigations on both membranes. The cross-section image of CTA membrane from $\mathrm{HTI}$ is shown in Figure 4. It is thin film (around $50 \mu \mathrm{m}$ ) that consists of a polyester mesh support and CTA active layer. The water flux of CTA membrane from HTI is $18.6 \mathrm{~L} \mathrm{~m}^{-2} \mathrm{~h}^{-1}$ using $\mathrm{DI}$ water and $0.5 \mathrm{M} \mathrm{NaCl}$ as feed solution and draw solution, respectively [34]. The power density of such membrane reached up to $1.3 \mathrm{Wm}^{-2}$ [27].

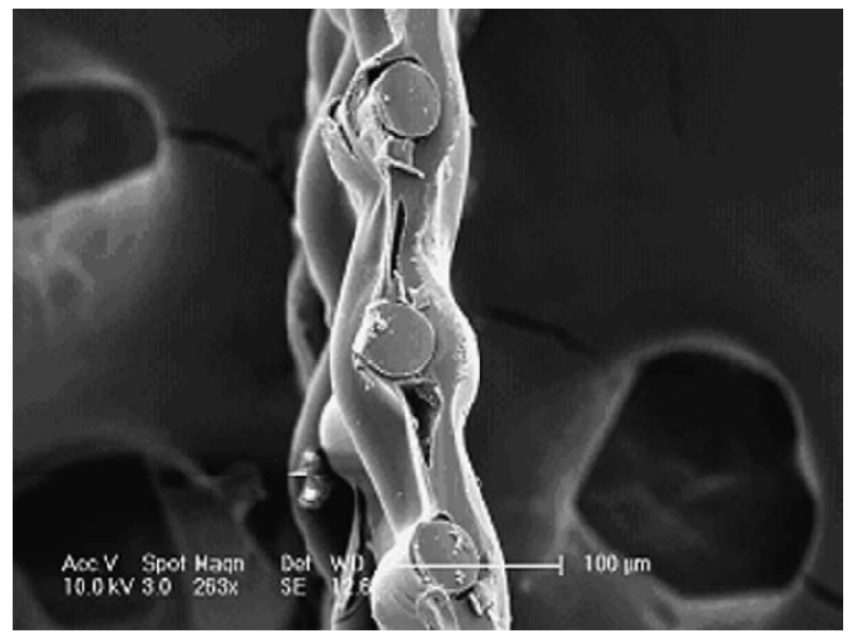

Figure 4: SEM image of the cross-section of CTA membrane from HTI [35].

Lately, Chung and co-workers have developed a number of cellulose ester-based membranes (hollow fiber and flat sheet modules) for FO applications [29, 36-38]. The methods are quite similar for preparing these cellulose derived membranes: phase inversion and then hot water annealing (at $60-95^{\circ} \mathrm{C}$ ). They found that the obtained FO membranes have two active skin layers, which are able to reduce ICP effect on the membrane performance and a mathematic model was developed based on this kind of double-skinned FO membrane [29, 37, 39]. The preliminary test showed high water flux which is $48.2 \mathrm{~L} \mathrm{~m}^{-2} \mathrm{~h}^{-1}$ and low reverse salt diffusion using quite high concentration of divalent salt solution $\left(5.0 \mathrm{M} \mathrm{MgCl}_{2}\right)$ as draw solution at $22{ }^{\circ} \mathrm{C}$. The same research group also observed that the interaction between the polymer and the casting substrate, which played an important role in the morphology of the membrane during the preparation 
[29]. In addition, Sairam et al. used the same phase inversion method to develop flat sheet FO membranes with cellulose acetate [40]. They tried using lactic acid, maleic acid and zinc chloride as pore-forming agents and cast the membrane onto nylon fabric at different annealing temperatures. They found that the prepared membrane using zinc chloride as the pore-forming agent had relatively good FO performance.

The limitations of CA membranes must be taken into account for the development of PRO membrane including the biological attack and solution $\mathrm{pH}$ (4-6), temperature $\left(<35^{\circ} \mathrm{C}\right)$ due to the hydrolysis propensity.

\section{THIN FILM COMPOSITE MEMBRANES}

Recently, various types of flat-sheet of composite and hollow fiber membranes were prepared for $\mathrm{FO}$ and PRO applications [34, 41-47]. In general, the strategy of preparing those membranes is based on the techniques for the fabrication of RO membrane, namely the porous support layer and the polyamide thin active layer are prepared using phase inversion method and interfacial polymerization, respectively.

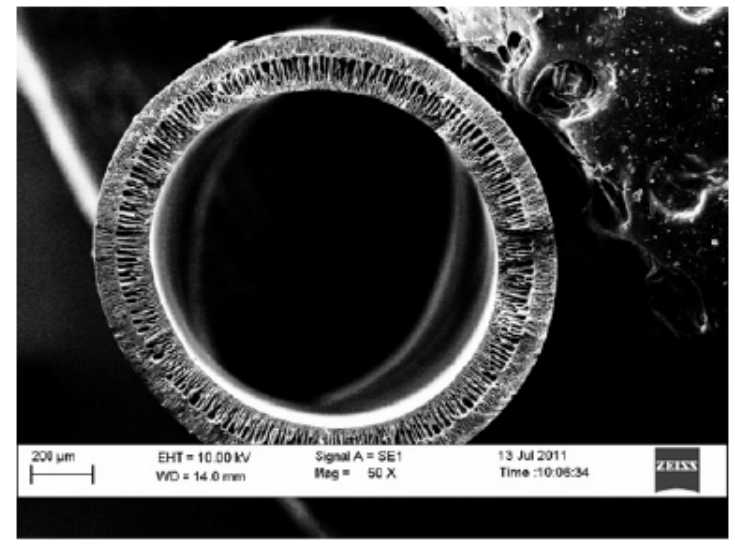

(a)

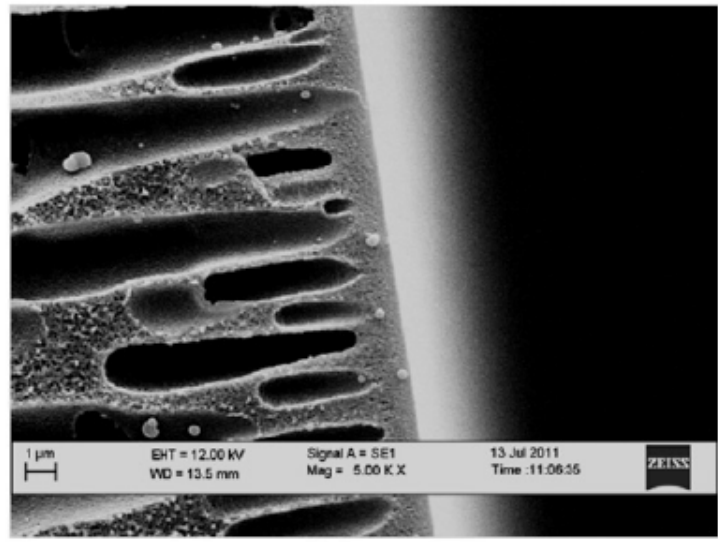

(c)
The Elimelech's group in Yale University investigated the morphology effect of polysulfone porous support layer on the membrane performance for FO. Their results suggested that both polymer concentration and the composition of polymer solvent affect the morphology of micro-porous support layer [43]. It appeared that the finger-like macrovoids structure in the support layer is favourable for the FO application. Later, the same composite flat sheet membrane consist of a thin polyamide active layer and polysulfone porous support layer was used for PRO and achieved 5.7-10.0 $\mathrm{Wm}^{-2}[2,47,48]$. The high power density was attributed to the tailored structure of polyamide active layer for the PRO application with moderate reverse solute diffusion and the highly porous structure of support layer [47].

Wang and co-workers prepared a polyethersulfone (PES) hollow fiber substrate and it was incorporated with polyamide active layer to form a PRO membrane as shown in Figure 5 [23]. The water flux of this hollow fiber membrane reached $40.6 \mathrm{~L} \mathrm{~m}^{-2} \mathrm{~h}^{-1}$ using $10.0 \mathrm{mM}$ and $5.0 \mathrm{M} \mathrm{NaCl}$ solution as feed and draw solution,

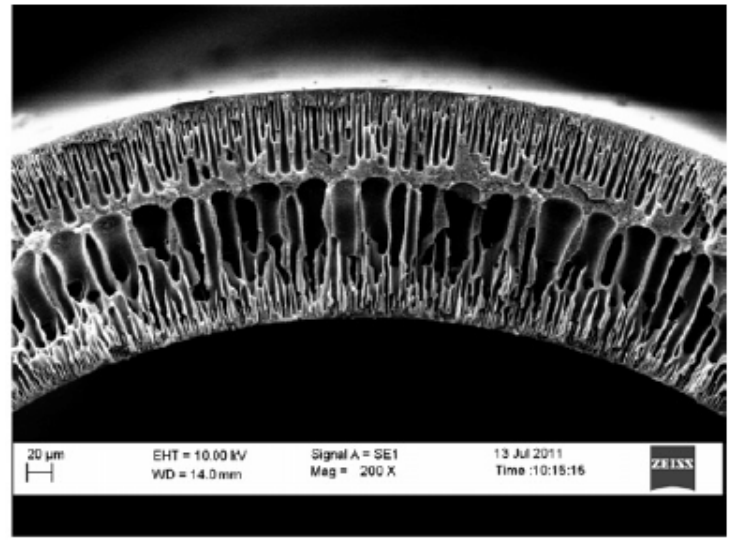

(b)

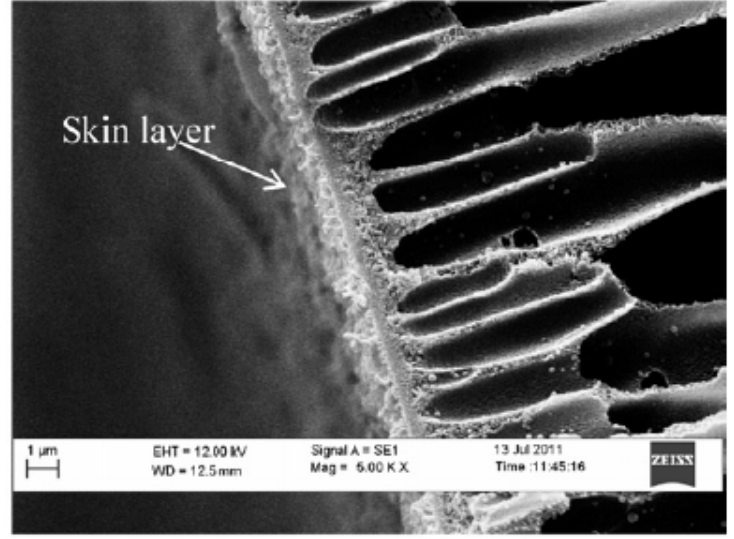

(d)

Figure 5: SEM images of hollow fiber membrane [23]. 
respectively. The simulated power density can be as high as $10.6 \mathrm{Wm}^{-2}$ using seawater brine $(1.0 \mathrm{M} \mathrm{NaCl})$ and wastewater brine $(40.0 \mathrm{mM} \mathrm{NaCl})$. They also investigated the surface of the substrate which suggested that a substrate with $<300 \mathrm{kDa}$ Molecular weight cut off (MWCO) should be preferred to obtain a good semipermeable skin [49].

\section{CHALLENGES AND PERSPECTIVES}

The development of membrane holds the key to the future of PRO power generation and its success will, in turn, have a great influence on FO for other applications such as desalination, food industry and waste water treatment. So far, the most of significant reports on the membrane development are from Elemelech's group in Yale University and research groups from Singapore. TFC membranes are promising for the PRO application in terms of water flux and power density. The state of the art TFC membranes yield over $10.0 \mathrm{~W} \mathrm{~m}^{-2}$ which much higher than the expected value $\left(5 \mathrm{~W} \mathrm{~m}^{-2}\right)$, and this stimulates a great motivation for building power plant based on these membranes. However, Logan and Elimelech pointed out that the energy consumption needs to be taken into account for pre-treating the fresh water and sea water in order to avoid membrane fouling. Thus, it is critical to improve the contamination resistance of the membrane, particularly the active skin layer [2]. There hasn't been any open literature reports such issue in details and how is it going to affect a PRO power plant in technical and economical ways.

Based on above discussions, the following suggestions are given in order to develop high performance PRO membranes:

- $\quad$ Reduce the ICP from micro-porous support layer

There are still not enough reports on the support layer to cover all the aspects that may affect the water flux, e.g. only few reports on the hydrophilicity of the porous support layer. The higher water flux is beneficial to reduce the membrane fouling in membrane separation processes.

- Novel skin active layer

Most of reports are using PA as active layer and such material has been approved to be sensitive to chlorine and other oxidants from previous RO studies. To implement this membrane for PRO applications, it is critical to develop new skin active layer with high resistance of contaminations as well as biological fouling.

- $\quad$ ECP, module configuration

ECP starts becoming predominant for future PRO applications due to higher water flux of the membrane. In $\mathrm{RO}$, there are numerous studies on operational procedures. However, the water flux in RO processes is much lower than PRO using the state of the art TFC membranes. It is important to investigate the new module design as well as operating procedures.

\section{REFERENCES}

[1] Pattle RE. Production of Electric Power by mixing Fresh and Salt Water in the Hydroelectric Pile. Nature 1954; 174(4431): 660-60.

http://dx.doi.org/10.1038/174660a0

[2] Logan BE, Elimelech M. Membrane-based processes for sustainable power generation using water. Nature 2012; 488(7411): 313-19

http://dx.doi.org/10.1038/nature11477

[3] Zhao S, et al. Recent developments in forward osmosis: Opportunities and challenges. J Membr Sci 2012; 396(0): 1 21.

http://dx.doi.org/10.1016/j.memsci.2011.12.023

[4] Loeb S. Osmotic power plants. Science 1975; 189(4203): 654-55.

http://dx.doi.org/10.1126/science.189.4203.654

[5] Loeb S, Van Hessen F, Shahaf D. Production of energy from concentrated brines by pressure retarded osmosis. II. Experimental results and projected energy costs. J Membr Sci 1976; 1(3): 249-69. http://dx.doi.org/10.1016/S0376-7388(00)82271-1

[6] Loeb S, Mehta GD, A two-coefficient water transport equation for pressure-retarded osmosis. J Membr Sci 1978; 4(0): 351-62.

http://dx.doi.org/10.1016/S0376-7388(00)83313-X

[7] Loeb S, Honda T, Reali M. Comparative mechanical efficiency of several plant configurations using a pressureretarded osmosis energy converter. J Membr Sci 1990; 51(3): 323-35. http://dx.doi.org/10.1016/S0376-7388(00)80354-3

[8] Loeb $\mathrm{S}$, et al. Effect of porous support fabric on osmosis through a Loeb-Sourirajan type asymmetric membrane. J Membr Sci 1997; 129(2): 243-49. http://dx.doi.org/10.1016/S0376-7388(96)00354-7

[9] Loeb S, Bloch MR. Countercurrent flow osmotic processes for the production of solutions having a high osmotic pressure. Desalination 1973; 13(2): 207-15. http://dx.doi.org/10.1016/S0011-9164(00)82045-7

[10] Loeb S. Energy production at the Dead Sea by pressureretarded osmosis: Challenge or chimera? Desalination 1998; 120(3): 247-62.

http://dx.doi.org/10.1016/S0011-9164(98)00222-7

[11] Loeb S. Large-scale power production by pressure-retarded osmosis, using river water and sea water passing through spiral modules. Desalination 2002; 143(2): 115-22. http://dx.doi.org/10.1016/S0011-9164(02)00233-3

[12] McGinnis RL, McCutcheon JR, Elimelech M. A nove ammonia-carbon dioxide osmotic heat engine for power generation. J Membr Sci 2007; 305(1-2): 13-19. http://dx.doi.org/10.1016/..memsci.2007.08.027

[13] http://www.statkraft.com/ 
[14] Lee KL, Baker RW, Lonsdale HK. Membranes for power generation by pressure-retarded osmosis. J Membr Sci 1981. 8(2): 141-71. http://dx.doi.org/10.1016/S0376-7388(00)82088-8

[15] McCutcheon JR, Elimelech M. Modeling water flux in forward osmosis: Implications for improved membrane design. AIChE J 2007; 53(7): 1736-44.

http://dx.doi.org/10.1002/aic.11197

[16] Cath TY, Childress AE, Elimelech M. Forward osmosis: Principles, applications, and recent developments. J Membr Sci 2006; 281(1-2): 70-87.

http://dx.doi.org/10.1016/j.memsci.2006.05.048

[17] McCutcheon JR, McGinnis RL, Elimelech M. Desalination by ammonia-carbon dioxide forward osmosis: Influence of draw and feed solution concentrations on process performance. $J$ Membr Sci 2006; 278(1-2): 114-23.

http://dx.doi.org/10.1016/j.memsci.2005.10.048

[18] McCutcheon JR, Elimelech M. Influence of concentrative and dilutive internal concentration polarization on flux behavior in forward osmosis. J Membr Sci 2006; 284(1-2): 237-47. http://dx.doi.org/10.1016/..memsci.2006.07.049

[19] Zhao S, Zou L. Relating solution physicochemical properties to internal concentration polarization in forward osmosis. J Membr Sci 2011; 379(1-2): 459-67.

http://dx.doi.org/10.1016/j.memsci.2011.06.021

[20] McCutcheon JR, Elimelech M. Influence of membrane support layer hydrophobicity on water flux in osmotically driven membrane processes. J Membr Sci 2008; 318(1-2): 458-66. http://dx.doi.org/10.1016/..memsci.2008.03.021

[21] Mehta GD, Loeb S. Performance of permasep B-9 and B-10 membranes in various osmotic regions and at high osmotic pressures. J Membr Sci 1978; 4(0): 335-49.

http://dx.doi.org/10.1016/S0376-7388(00)83312-8

[22] Mehta GD, Loeb S. Internal polarization in the porous substructure of a semipermeable membrane under pressureretarded osmosis. J Membr Sci 1978; 4(0): 261-65. http://dx.doi.org/10.1016/S0376-7388(00)83301-3

[23] Chou S, et al. Thin-film composite hollow fiber membranes for pressure retarded osmosis (PRO) process with high power density. J Membr Sci 2012; 389(0): 25-33. http://dx.doi.org/10.1016/j.memsci.2011.10.002

[24] $\mathrm{Xu} \mathrm{Y,} \mathrm{et} \mathrm{al.} \mathrm{Effect} \mathrm{of} \mathrm{draw} \mathrm{solution} \mathrm{concentration} \mathrm{and}$ operating conditions on forward osmosis and pressure retarded osmosis performance in a spiral wound module. $\mathrm{J}$ Membr Sci 2010; 348(1-2): 298-309. http://dx.doi.org/10.1016/j.memsci.2009.11.013

[25] Yong JS, Phillip WA, Elimelech M. Coupled reverse draw solute permeation and water flux in forward osmosis with neutral draw solutes. J Membr Sci 2012; 392-393(0): 9-17. http://dx.doi.org/10.1016/j.memsci.2011.11.020

[26] Hancock NT, Cath TY. Solute Coupled Diffusion in Osmotically Driven Membrane Processes. Environ Sci Technol 2009; 43(17): 6769-75. http://dx.doi.org/10.1021/es901132x

[27] Gerstandt K, et al. Membrane processes in energy supply for an osmotic power plant. Desalination 2008; 224(1-3): 64-70. http://dx.doi.org/10.1016/j.desal.2007.02.080

[28] Post JW, et al. Salinity-gradient power: Evaluation of pressure-retarded osmosis and reverse electrodialysis. J Membr Sci 2007; 288(1-2): 218-30. http://dx.doi.org/10.1016/..memsci.2006.11.018

[29] Zhang $S$, et al. Well-constructed cellulose acetate membranes for forward osmosis: Minimized internal concentration polarization with an ultra-thin selective layer. J Membr Sci 2010; 360(1-2): 522-35. http://dx.doi.org/10.1016/j.memsci.2010.05.056
[30] Geise GM, et al. Water purification by membranes: The role of polymer science. J Polym Sci Part B: Polym Phys 2010; 48(15): 1685-18. http://dx.doi.org/10.1002/polb.22037

[31] Reid CE, Breton EJ. Water and ion flow across cellulosic membranes. J Appl Polym Sci 1959; 1(2): 133-43. http://dx.doi.org/10.1002/app.1959.070010202

[32] Reid CE, Kuppers JR. Physical characteristics of osmotic membranes of organic polymers. J Appl Polym Sci 1959; 2(6): 264-72.

http://dx.doi.org/10.1002/app.1959.070020602

[33] Loeb S, Sourirajan S. Sea Water Demineralization by Means of an Osmotic Membrane, in Saline Water Conversion?II. Am Chem Soc 1963; 117-32. http://dx.doi.org/10.1021/ba-1963-0038.ch009

[34] Wang $R$, et al. Characterization of novel forward osmosis hollow fiber membranes. J Membr Sci 2012; 355(1-2): 15867.

[35] McCutcheon JR, McGinnis RL, Elimelech M. A novel ammonia-carbon dioxide forward (direct) osmosis desalination process. Desalination 2005; 174(1): 1-11. http://dx.doi.org/10.1016/i.desal.2004.11.002

[36] Su J, et al. Cellulose acetate nanofiltration hollow fiber membranes for forward osmosis processes. J Membr Sci 2012; 355(1-2): 36-44.

[37] Wang KY, Ong RC, Chung T-S. Double-Skinned Forward Osmosis Membranes for Reducing Internal Concentration Polarization within the Porous Sublayer. Indust Eng Chem Res 2010; 49(10): 4824-31. http://dx.doi.org/10.1021/ie901592d

[38] Zhang S, et al. Molecular design of the cellulose ester-based forward osmosis membranes for desalination. Chem Eng Sci 2011; 66(9): 2008-18. http://dx.doi.org/10.1016/j.ces.2011.02.002

[39] Tang CY, et al. Modeling double-skinned FO membranes. Desalination 2011; 283(0): 178-86. http://dx.doi.org/10.1016/i.desal.2011.02.026

[40] Sairam M, et al. Method for the preparation of cellulose acetate flat sheet composite membranes for forward osmosis-Desalination using $\mathrm{MgSO}_{4}$ draw solution. Desalination 2011; 273(2-3): 299-307. http://dx.doi.org/10.1016/j.desal.2011.01.050

[41] Wang KY, Chung T-S, Qin J-J. Polybenzimidazole (PBI) nanofiltration hollow fiber membranes applied in forward osmosis process. J Membr Sci 2007; 300(1-2): 6-12. http://dx.doi.org/10.1016/j.memsci.2007.05.035

[42] Setiawan L, et al. Fabrication of novel poly(amide-imide) forward osmosis hollow fiber membranes with a positively charged nanofiltration-like selective layer. J Membr Sci 2010 369(1-2): 196-205.

[43] Tiraferri A, et al. Relating performance of thin-film composite forward osmosis membranes to support layer formation and structure. J Membr Sci 2011; 367(1-2): 340-52. http://dx.doi.org/10.1016/j.memsci.2010.11.014

[44] Wang KY, Chung T-S, Amy G. Developing thin-filmcomposite forward osmosis membranes on the PES/SPSf substrate through interfacial polymerization. AIChE J 2012; 58(3): 770-81.

http://dx.doi.org/10.1002/aic.12635

[45] Wei J, et al. Synthesis and characterization of flat-sheet thin film composite forward osmosis membranes. J Membr Sci 2011; 372(1-2): 292-302. http://dx.doi.org/10.1016/j.memsci.2011.02.013

[46] Wei J, et al. Influence of monomer concentrations on the performance of polyamide-based thin film composite forward osmosis membranes. J Membr Sci 2011; 381(1-2): 110-17. http://dx.doi.org/10.1016/j.memsci.2011.07.034 
[47] Yip NY, et al. Thin-Film Composite Pressure Retarded Osmosis Membranes for Sustainable Power Generation from Salinity Gradients. Environ Sci Technol 2011; 45(10): 436069.

http://dx.doi.org/10.1021/es104325z

[48] Yip NY, Elimelech M. Performance Limiting Effects in Power Generation from Salinity Gradients by Pressure Retarded
Osmosis. Environ Sci Technol 2011; 45(23): 10273-82. http://dx.doi.org/10.1021/es203197e

[49] Shi L, et al. Effect of substrate structure on the performance of thin-film composite forward osmosis hollow fiber membranes. J Membr Sci 2011; 382(1-2): 116-23. http://dx.doi.org/10.1016/j.memsci.2011.07.045 